\title{
Low progesterone levels and ovulation by ultrasound assessment in infertile patients
}

\author{
Eliane G. M. Sanchez ${ }^{1}$, Christiane R. Giviziez ${ }^{1}$, Hugo M. Sanchez ${ }^{1}$, Patrícia L. S. Agostinho ${ }^{1}$, Patrícia S. Barros ${ }^{1}$, \\ Mário S. Approbato ${ }^{2}$
}

${ }^{1}$ Federal University of Goiás. Medical School. University Hospital. Gynecology and Obstetrics Department. Human Reproduction Lab - Goiânia (GO) - Brazil

${ }^{2}$ Federal University of Goiás - Jataí (GO) - Brazil

\begin{abstract}
Objective: To assess the correlation between low levels of progesterone and ovulation by ultrasound monitoring in infertile patients with regular menstrual cycles.

Methods: Case-control study. The sample consisted of 302 women aged 20-40 years, treated from 2000 to 2014 in the Human Reproduction Laboratory of the University Hospital of the Federal University of Goiás and in the Department of Gynecology and Obstetrics in Goiânia, Goiás. Data collection was performed by analysis of physical records (Medical Records and Health Information Services) and electronic ones $\left(\right.$ Sisfert $^{\circ}$, 2004) after approval by a Human Research Ethics Committee. Patients were classified according to their ovulatory status, evaluated by progesterone levels and ultrasound monitoring and divided into two groups: Group I (anovulatory cycle patients, $n=74$ ) and Group II (ovulatory patients, $n=228$ ). In both groups associations were made between the percentage of patients with normal progesterone $(\geq 10 \mathrm{ng} / \mathrm{ml})$ and percentage of patients with low progesterone (5.65 - 9.9 $\mathrm{ng} / \mathrm{ml}$ ). The groups were paired for comparisons related to age, body mass index, duration of infertility, follicle stimulating hormone (FSH), thyroid stimulating hormone (TSH), luteinizing hormone (LH) and estradiol (E2).

Results: There was a significant association between the percentage of ovulation by ultrasound monitoring and the percentages of patients who presented low levels of progesterone.

Conclusions: The study suggests that low serum levels of progesterone are associated with low percentage of ovulation in infertile women with regular menstrual cycles and women with unexplained infertility.
\end{abstract}

Keywords: Infertility, Ovulation, Regular cycles, Low progesterone.

\section{INTRODUCTION}

The World Health Organization (WHO) defines infertility as the absence of pregnancy after one year or more of sexual relations with no use of contraceptives (Rowe et al., 1993).

It is estimated that there are from 50 to 80 million infertile couples in the world, with about two million new cases per year (Gonçalves, 2005). This event is experienced by $8-15 \%$ of couples in general. In Brazil, more than 278,000 couples have some difficulty in conceiving a child at some point in their childbearing age.

The causes of infertility in women could be due to anatomical factors related to the uterus or the fallopian tubes; hormonal causes that affect the hypothalamic-pituitary-ovarian axis; and sterility without apparent cause (ESCA). It is believed that these factors correspond to $35 \%$ of infertility causes in women, $35 \%$ in men; $20 \%$ are associated with female and male issues, and $10 \%$ with ESCA.

Ovulatory dysfunctions represent the main causes of female infertility, accounting for up to $40 \%$ of them
(ASRM, 2012). Among the causes, hormonal changes are the most important, especially for infertility. Among them, we can highlight Polycystic Ovarian Syndrome (PCOS), hypothyroidism, hyperprolactinemia, low levels of progesterone (P4), among others (McLaren, 2012).

Progesterone (P4) is a hormone produced after puberty, by the corpus luteum (CL) and by the placenta during the pregnancy and it acts in the regulation of normal female reproductive functions. The endometrium is prepared In the womb, facilitating deployment and maintenance of early pregnancy (Al-Asmakh, 2007). For this reason P4 plays a vital role in female fertility and low levels of it can significantly decrease the chances of pregnancy due the probable influence on endometrial development (ASRM, 2015).

P4 was first associated with the corpus luteum by the huge production of this steroid after ovulation. Currently, it is known that its secretion starts from the moment a mature ovarian follicle is stimulated by LH release (Ke, 2014; Moreira, 2014).

According to the ASRM (2012), ovulatory function can be evaluated by assessing P4 levels in the bloodstream, but it should be obtained at appropriate times in the menstrual cycle.

It is usually recommended that P4 be dosed from 7 to 9 days after the suspected ovulation. Some authors consider this event to happen with P4 levels starting at 3ng/ $\mathrm{ml}$ (Guttmacher et al., 1956; Garzia et al., 2004; ASRM, 2012; McLaren, 2012). The World Health Organization (Rowe et al., 1993) stresses ovulatory P4 levels $\geq 5.65 \mathrm{ng} /$ $\mathrm{ml}$, measured between the 20th and 24th days of a 28-day cycle. Serum progesterone levels higher than $10 \mathrm{ng} / \mathrm{ml}$ are used as a parameter to measure ovulatory function by the ASRM (2012).

P4 levels may suffer discrete increases and cause the non-rupture of a luteinized follicle (LUF). In this event, the follicle develops itself normally, grows and matures, but does not break to release the ovum; however, there may be a P4 secretion, such as a follicle that brakes, originating the $\mathrm{CL}$. Thus, there is no ovulation, but the follicle secretes P4, making serum levels increase slightly. In this case, values don't reach the $10 \mathrm{ng} / \mathrm{ml}$ and it establishes a low level of P4 (Van Zonneveld et al., 1994) causing anovulation.

Low P4 is one of the causes of anovulation and a subtle cause of female infertility (Young \& Lessey, 2010), which can be characterized by insufficient P4 secretion to maintain the endometrium, preventing implantation and normal embryo growth (Sonntag \& Ludwig 2012; Schliep, 2014). It can be found by P4 dosing and through invasive procedures or sophisticated ovulation assessment equipment (Mardesic, 1990).

There's no standard characterization yet to evaluate progesterone secretion during the luteal phase in normal fertile women and there is no established minimum P4 value to determine an adequate luteal function. Furthermore, it is known that the corpus luteum function var- 
ies from cycle to cycle, but if properly collected, serum progesterone levels can be useful in clinical diagnosis to assess the adequacy of the luteal phase (ASRM, 2015).

Some authors suggest that the diagnosis of decreased P4 can be done by levels $<10 \mathrm{ng} / \mathrm{ml}$ (Van Zonneveld et al., 1994), others indicate values $<8 \mathrm{ng} / \mathrm{ml}$ (Litwack \& Begley, 2001); and Arce et al. (2011) suggest values between 7.9 - $10 \mathrm{ng} / \mathrm{ml}$ may indicate LUF. Although there is certain proximity between P4 values indicative of LUF, there is still no consensus about low P4 threshold levels.

The identification of anovulatory cycles is a challenge for healthcare professionals. Ovulation prediction or confirmation may also be obtained by serial monitoring through transvaginal ultrasound, to measure follicle growth and allow the evaluation of follicular rupture (ASRM, 2012).

Transvaginal US is of the gold standard for ovulation diagnosis during the menstrual cycle, but difficult to be used in epidemiological studies. In the absence of this method, measurements of concentrations of reproductive hormones are commonly used to identify the ovulatory status in research, among them the measure of P4 levels stands out.

A combination of methods for measuring ovulation has been recommended in order to obtain a more accurate diagnosis. The Labrep (Human Reproduction Laboratory) HC/UFG (University Hospital of the Federal University of Goiás) associates monitoring of ovarian follicles through ultrasound and the dosage of P4 serum levels to diagnose ovulation, although women with low P4 are not necessarily submitted to ultrasound check, which may be responsible for inconsistent ovulatory diagnostics. This study is justified by the lack of literature showing the low progesterone influence in the ovulation of infertile women with regular cycles. Thus, the aim of this study was to evaluate the association between low levels of P4 and US ovulation assessment in infertile patients with regular cycles suffering from unexplained infertility.

\section{MATERIALS AND METHODS}

This is a case-control study. There were 302 patients selected, aged between 20 and 40 years, seen between
2000 and 2014 in the Human Reproduction Laboratory of the University Hospital of the Federal University of Goiás/UFG and in the Clinic of Gynecology and Obstetrics of the private healthcare network in Goiania - Goias.

Data was collected from the medical charts stored in the Medical Office Management System (SAMIS) and from the electronic charts from the Sisfert $^{\odot}$ database, which started after approval by the Human Research Ethics Committee HC/UFG.

Women who had been evaluated by ultrasound and had presented both regular progesterone levels and ovulatory cycles were included; women with FSH levels above 9.9 $\mathrm{mIU} / \mathrm{mL}$ (basal $\mathrm{FSH}=1.4$ to $9.9 \mathrm{mIU} / \mathrm{mL}$ ) were excluded, as were those with TSH higher than 4.7 (basal $=0$, 4 and $5 \mathrm{mIU} / \mathrm{L}$ ) (Garber et al., 2012), those with Polycystic Ovarian Syndrome with oligomenorrhea or amenorrhea, users of medicines that would interfere with ovulation and women under 20 and over 40 years of age.

The patients were broken down into two groups according to their ovulatory state determined by transvaginal ultrasound monitoring: Group I $(n=74)$ anovulatory, comprising women who had P4 levels of $5.65-9.9 \mathrm{ng} / \mathrm{ml}$ and lack of follicular collapse - evaluated by monitoring with intravaginal US. Group II $(n=228)$ ovulatory, consisted of women with P4 levels $\geq 10 \mathrm{ng} / \mathrm{mL}$ and follicular collapse evaluated by monitoring through US (ASRM, 2012). Among those groups, two groups were evaluated to obtain the percentage of patients with normal ovulatory progesterone $(\geq 10 \mathrm{ng} / \mathrm{mL})$ and the percentage of patients with low progesterone ( 5.65 to $9.9 \mathrm{ng} / \mathrm{mL}$ ) considered as LUF in the study. Those groups were paired for comparison in relation to age, body mass index, infertility duration, Follicle Stimulating Hormone - FSH $(\mathrm{ng} / \mathrm{mL})$, Thyroid-stimulating Hormone - TSH $(\mathrm{mIU} / \mathrm{mL})$, Luteinizing Hormone - LH ( $\mathrm{mIU} / \mathrm{mL})$ Estradiol (E2) $(\mathrm{pg} / \mathrm{mL})$, according to Table 1.

The statistical analysis was performed using IBM SPSS Statistics 20.0 (Statistical Packages for Social Sciences, USA) and the Bioestat (version 5.3). We used the Chi-square test with a confidence interval of $95 \%$ and $P=0.05$ for significance level. Where the statistical anal-

Table 1. Distribution of patients according to LUF and Non-LUF groups comparison (confounding variables). HC-UFG / Mater Clinic, Goiania 2000-2014.

\begin{tabular}{|l|c|c|c|}
\hline \multicolumn{1}{|c|}{ General features } & LUF $(\mathbf{n = 7 4 )}$ & Non-LUF (n=228) & $\boldsymbol{P}$ \\
\hline Age & $31.54 \pm 4.71$ & $31.85 \pm 4.21$ & 0.32 \\
\hline BMI & $24.83 \pm 3.85$ & $23.88 \pm 3.93$ & 0.07 \\
\hline LH & $4.56 \pm 6.51$ & $4.61 \pm 2.74$ & 0.06 \\
\hline FSH & $6.26 \pm 1.45$ & $5.98 \pm 1.68$ & 0.07 \\
\hline TSH & $2.50 \pm 0.93$ & $2.16 \pm 1.19$ & 0.75 \\
\hline Estradiol ( $\left.E_{2}\right)$ & $51.84 \pm 35.82$ & $54.34 \pm 51.09$ & 0.12 \\
\hline Infertility duration & $67.61 \pm 47.81$ & $64.17 \pm 46.95$ & 0.28 \\
\hline BMI (Body Mass Index); LH (luteinizing hormone) FSH (Follicle Stimulating Hormone); TSH (thyroid-stimulating hormone) \\
\hline
\end{tabular}

Table 2. Distribution of the second ovulation according to patients' P4 levels (normal and $5.65-9.9 \mathrm{ngml}$ ) from the LabRep HC - UFG / Mater Clinic. Goiania, 2000-2014.

\begin{tabular}{|c|c|c|c|c|c|}
\hline LUF (P4) & $\begin{array}{c}\text { Ovulation } \\
\text { (US) }\end{array}$ & $\begin{array}{c}\text { Anovulation } \\
\text { (US) }\end{array}$ & Total & $\mathbf{X}^{\mathbf{2}}$ & $\boldsymbol{P}$ \\
\hline Group I (LUF) & $50(20.4 \%)$ & $24(42.1 \%)$ & 74 & 11.76 & 0.001 \\
\hline Group II (No LUF) & $195(79.6 \%)$ & $33(57.9 \%)$ & 228 & & \\
\hline Total & $\mathbf{2 4 5}$ & $\mathbf{5 7}$ & $\mathbf{3 0 2}$ & & \\
\hline
\end{tabular}

P4 (progesterone); X2 (chi-square value). Group I - LUF (P4 5.65 - 9.9 ng/ml); Group II - No LUF (P4 $\geq 10 \mathrm{ng} / \mathrm{ml})$. IC $95 \%(0.191-0.649)$. OR (odds ratio) $=0.353$ 
ysis was not performed, we calculated the mean value and the standard deviation of the variables under study.

\section{RESULTS}

The results obtained are presented in tables as follows. The comparability of the two populations studied is shown on Table 1. Comparability tests did not show statistically significant differences $(P>0.05)$.

Table 2 shows a significant association between the percentage of ovulation through ultrasound and the percentage of patients who had low progesterone levels $(\mathrm{OR}=0.353)$; IC (95\%): $0.191-0.649$. $P=0.001$.

\section{DISCUSSION}

This study has shown that low P4 levels are associated with significant decreases in ovulation in infertile women with regular cycles, women with unexplained infertility. This fact was explained by Mesen \& Young (2015) when they reported that a defected luteal phase may decrease P4 levels and the fertility in women.

It's interesting to highlight that, despite the pulsatile release of $\mathrm{P} 4$, its low levels on a single measurement may not always indicate ovulatory disorders (ASRM, 2012). On the other hand, this present study found ovulatory changes confirmed by monitoring through ultrasound in $42.1 \%$ of women who presented low P4.

Studies which evaluate P4 values in women with regular cycles are unusual (Fatemi, 2009; Young \& Lessey, 2010). This study evaluated P4 levels in this group of women. While normal P4 values are related to regular cycles and ovulation, lower values may reflect the presence of unruptured luteinized follicle (LUF) (Schliep, 2014). In a study by Litwack \& Begley (2001) the ovulatory status was evaluated considering the P4 levels for three menstrual cycles in 543 patients with infertility history longer than two years. From the population studied so far, 461 (90.2\%) had normal ovulatory cycles confirmed by ultrasound monitoring and $50(9.8 \%)$ had anovulatory cycles. In this study, values considered suggestive of ovulation were the ones with P4 levels $>8 \mathrm{ng} / \mathrm{ml}$, and P4 levels $<8 \mathrm{ng} / \mathrm{mL}$ were considered low values. Out of the population being studied, 292 women (63.9\%) had normal P4 and 165 (36.1\%) had low P4. From the group with apparently normal P4 values, $7.2 \%$ of women got pregnant when compared to $3.6 \%$ of women with low P4. Our study showed significant reduction $(P<0.001)$ in the fertility of patients with low progesterone levels. It also corroborates the study by Hamilton et al. (1987), who evaluated 201 ovulatory cycles in 170 infertile women by measuring ovarian follicles through ultrasound and P4 levels. In our study we found LUF in $71 \%$ of the cycles in which the P4 levels were lower than $10 \mathrm{ng} / \mathrm{ml}$, and in $7.9 \%$ of cycles in which P4 levels were higher than $10 \mathrm{ng} / \mathrm{ml}$. These data corroborate the results of the present study which also found LUF in cycles $(20.4 \%)$ in which P4 levels were over $10 \mathrm{ng} / \mathrm{ml}$. Eissa et al. (1987) studied ovulatory cycles in 45 subfertile women and found LUF in $19 \%$ of cycles, but neither reported P4 values used to determine LUF, nor highlighted the monitoring of the ovulatory follicle through US. The sensitivity and specificity of diagnostic methods of ovulation were evaluated by Mesen \& Young (2015), wherein they found that P4 levels stand out among other evaluating methods, including endometrial biopsy.

This study showed an association between anovulation through ultrasound and low levels of P4.

\section{CONCLUSIONS}

This study suggests that low progesterone levels are associated with a reduction in ovulation percentage in infertile women with regular menstrual cycles and women with unexplained infertility. The number $(n)$ of women used in the study favors greater emphasis on results found.

\section{CONFLICT OF INTERESTS}

No conflict of interest have been declared.

\section{Corresponding author:}

Eliane Gouveia de Morais Sanchez

Universidade Federal de Goiás. Faculdade de Medicina. Departamento de Ginecologia e Obstetrícia. Hospital das Clínicas.

Laboratório de Reprodução Humana

Goiânia (GO) - Brasil.

E-mail: egmfisio@yahoo.com.br

\section{REFERENCES}

Al-Asmakh M. Reproductive function of progesterone. Middle East Fertil Soc. 2007; 12:147-52.

Arce JC, Balen A, Platteau P, Pettersson G, Andersen A N. Mid-luteal progesterone concentrations are associated with live birth rates during ovulation induction. Reprod Biomed Online. $2011 ; 22: 449-56$.

ASRM - The Practice Committee of the American Society for Reproductive Medicine. Diagnostic evaluation of the infertile female: a committee opinion. Fertil Steril. 2012, 98:302-7.

ASRM - The Practice Committee of the American Society for Reproductive Medicine. Current clinical irrelevance of luteal phase deficiency: a committee opinion. Fertil Steril. 2015; 103: 27-32.

Eissa MK, Sawers RS, Docker MF. Characteristics and incidence of dysfunctional ovulation patterns detected by ultrasound. Fertil Steril. 1987; 4: 603-12.

Fatemi H M. Assessment of the luteal phase in stimulated and substituted cycles. Facts Views Vis Obgyn. 2009; 1: 30-46.

Guttmacher AF. Factors affecting normal expectancy of conception. J Am Med Assoc. 1956; 16: 855-64.

Garzia E, Borgato S, Cozzi V, Doi P, Bulfamante G, Persani L, Cetin I. Lack of expression of endometrial prolactin in early implantation failure: a pilot study. Hum Reprod. 2004; 19:1911-6.

Gonçalves J. Avaliação do casal infértil. Rev Port Clin Geral. 2005; 21:493-503.

Hamilton CJCM, Evers JLH, de Haan J. Ovulatory disturbances in patients with luteal insufficiency. Clin. Endocrinol. 1987; 26:129-36.

Ke, R.W. Endocrine Basis for Recurrent Pregnancy Loss. Obstet Gynecol Clin North Am. 2014; 41:103-12.

Litwack G, Begley T, eds. Vitamins and Hormones. Academic Press, San Diego, CA; 2001

Mardesic T. [Unruptured luteinized follicle syndrome]. Zentralbl Gynakol. 1990; 112: 1133-41.

McLaren JF. Infertility Evaluation. Obstet Gynecol Clin North Am. 2012; 39: 453-63.

Mesen TB, Young SL. Progesterone and the Luteal Phase: A Requisite to Reproduction. Obstet Gynecol Clin North Am. 2015; 42:135-51 
Moreira RO. Fisiologia do Sistema reprodutor feminino. In: Wajchenberg BL, Larario, AC, Betti RTB. Tratado de Endocrinologia Clínica. 2.ed. AC Farmacêutica, São Paulo; 2014. p.636-54.

Rowe PJ, Comhaire FH, Hargreave TB, Mellouws HJ. WHO Manual for the standardized investigation and diagnosis of them infertile couple. New York. USA. 1993.

Schliep KC, Mumford SL, Hammoud AO, Stanford JB, Kissell KA, Sjaarda LA, Perkins NJ, Ahrens KA, Wactawski-Wende J, Mendola $P$, Schisterman EF. Luteal phase deficiency in regularly menstruating women: prevalence and overlap in identification based on clinical and biochemical diagnos- tic criteria. J Clin Endocrinol Metab. 2014;99: 1007-14.

Sonntag B, Ludwig M. An integrated view on the luteal phase: diagnosis and treatment in subfertility. Clin Endocrinol (Oxf). 2012; 77:500-7.

Van Zonneveld P, Te Velde ER, Koppeschaar HPF. Low luteal phase serum progesterone levels in regularly cycling women are predictive of subtle ovulation disorders. Gynecol Endocrinol. 1994;8:169-74

Young SL, Lessey BA. Progesterone function in human endometrium: clinical perspectives. Semin Reprod Med $2010 ; 28: 5-16$ 